\title{
Evaluating and Developing Quantitative Methods and Technical Skills in Master's Level Online Distance Learning Students: Experiences of a Teaching Enhancement Project Exploring Transition Challenges
}

\author{
Helen Durham \\ University of Leeds, $U K$
}

\begin{abstract}
This paper will share experiences and findings from a teaching enhancement project exploring students' 'readiness' for starting a taught postgraduate course in a discipline requiring strong quantitative methods and technical skills. The changing landscape of higher education and the diversity of students' academic, cultural and experiential backgrounds means that the transition to postgraduate level study can be more challenging, particularly where those students are distance learners. To gain an insight into students' perceptions into their readiness for study a survey was conducted on campus-based and online distance learning students enrolled on Master of Science courses at the University of Leeds. The survey sought to explore whether students felt that additional support at, or even before, the start of their studies would have resulted in a smoother transition and a more successful learning journey. The responses indicated that students lacked experience and confidence in certain areas, in particular programming (coding) and data management software. As part of the project a resource introducing students to modelling the spread of disease using the programming software 'Scratch' was created and piloted with online distance learning students. Feedback was extremely positive with the request for additional resources in a similar vein.
\end{abstract}

\section{Introduction}

As educators it is our aim to facilitate, enrich and enhance the learning experience of students from the transition stage of a new level of study through to their successful graduation. The author's experience of teaching taught postgraduate students has highlighted, however, that some students are not ready for the challenges that lie ahead as they step onto a Master of Science (MSc) degree. But is that perception a reality, and what are the students' views on their readiness for taught postgraduate studies as they reflect on their learning journey in the latter days of their course? Do those students recognize that there were gaps in their experience or academic background that could have been better supported in the early days of their study, or even before they started? How could course leaders help develop students' confidence and competency in skills where those gaps might exist? These questions formed the basis of a teaching enhancement project which sought to gain a better understanding of the needs and challenges of stepping onto a science-based taught postgraduate course where competency in handling quantitative data and good technical skills are paramount for a successful learning journey. With the changing landscape in higher education, in particular the expansion by universities into online distance learning (ODL) as a mode of delivery, these questions are particularly pertinent. For some students starting their postgraduate studies it may be many years since they last attended formal education and, for those enrolling on a part-time distance learning course, studying remotely can be a very challenging experience that requires students to have different qualities and motivations. Admission to a taught postgraduate course is not necessarily based on academic qualifications alone and prior work experience can sometimes tip the balance in favour of students who do not meet 'standard' academic entry requirements and this is a common scenario for students enrolling on the ODL course in Geographical Information Systems (GIS) at the University of Leeds [1]. The diverse academic, cultural and experiential backgrounds of incoming students can mean that the transition to postgraduate level study is challenging for some students [2]. Evaluating these transition challenges, and investigating how students can be better supported, increases the opportunity for knowledge and good practice to be shared with educators in the wider community.

This paper will share experiences from a teaching enhancement project, funded by the Leeds Institute for Teaching Excellence, which has been exploring whether students are appropriately prepared for a taught postgraduate course in a discipline requiring strong quantitative data handling and technical skills. The context of the project will be established and a summary 
provided of a survey undertaken to gain an insight into students' perception of their readiness for their chosen course. The results from the survey directed the focus of the next stage of the project, involving the development of a pilot pre-sessional resource distributed to ODL students and the subsequent assessment and reflection on the benefits of providing additional support in the pre-sessional, or transitional, period of study.

\section{Background}

Perceived and actual readiness for postgraduate study is pertinent to both campus-based and ODL students but it is the challenges of a changing landscape in Higher Education (HE) and the academic, cultural and experiential diversity of the student body, particularly those who choose to study by distance learning [3], that has provided the background for this teaching enhancement project. These challenges have been previously introduced [1] but will be further discussed in this section to provide the full context for this study.

\subsection{The changing landscape of $\mathrm{HE}$}

Distance-learning programmes are on the rise in HE. What was once viewed as an unconventional route to study in higher education is fast moving towards the conventional. Massive Open Online Courses (MOOCS), accredited MOOCS, and online distance learning programmes are all methods of student education that are shifting the traditional parameters of university study [1]. It has been speculated [3] that universities are seeing the potential of distance learning as a means to broaden their teaching portfolio and expand student numbers, even when the infrastructure that makes up the physical university is full to capacity. There may be the perception that distance learning involves less teaching, or more efficient teaching, and a source of easy revenue generation but those who already deliver online distance learning programmes may disagree; robust academic and administrative support structures needs to be in place to secure academic success and enhance the student experience [2].

Until more recent times, a prospective student wishing to broaden their knowledge and acquire higher education qualifications would probably enrol as a campus-based student at a university on a full or parttime basis. However, alternative study models have existed for many years, such as correspondence courses. In the United Kingdom (UK), the University of London broke new ground in 1858 with the establishment of the External System, reforming education access and opening up the possibility of gaining a degree without ever studying on-campus [4]. As a method of study, correspondence courses provided opportunities for those who had not been able to participate in the more conventional education system but they were not necessarily providing an equivalent experience that campus-based students might expect, offering limited interactivity and often aimed at a more niche market.

Over the last 50 years the Open University (OU) has been a pioneer in distance learning, asserting that it "changed the face of British higher education with its quality teaching materials, innovative pedagogy and exploitation of new technologies" [5]. Established in 1969, the OU augmented the learning experience by delivering television and radio tuition combined with correspondence courses and residential courses [6][7] and can be attributed to paving the way for distance learning to become a more accepted and frequently pursued route into gaining a higher education qualification.

Times have changed in a relatively short period to the benefit of those students who wish to study by distance learning. Approximately half of the world's population now has ready access to computers and the internet [8] and the Office for National Statistics reported that approximately $89 \%$ of adults in the UK had accessed the internet in the 3 months preceding the survey [9]. With technological and software advances enabling virtual learning environments, video streaming and interactive study experiences, such as discussion boards and web conferencing, the world of online distance learning is expanding. A recent study into the trends and patterns of distance learning among degree-awarding higher education institutions in the United States revealed that more than six million students took at least one distance course in 2015, almost $30 \%$ of students compared to $9.6 \%$ of students in 2002 [10]. It also reported that, in that same year, $14.3 \%$ of all students studied exclusively via distance learning courses. The study presents the headline figure that whilst overall distance enrolment has grown, campus-based enrolment has fallen by 5\% since 2012 .

\subsection{Student diversity}

An online distance learning course offers students the flexibility to keep many aspects of their lives at a status quo whilst gaining a qualification, but it does come with challenges for students as they adapt to this different approach to study [11][12] and are required to embrace new skills at a distance and often in (physical) isolation from their peers and tutors [1]. Induction resources can help manage study expectations and prepare students for their first module but additional support in the learning journey may be required where a course is science-based and a baseline of quantitative 
data handling and technical skills is assumed. It is only when students have commenced their study does it become evident that some are struggling to adapt and certain skills and aptitudes are lacking. But there are hurdles and lessons to be learnt for the educators too; guiding the student through their learning experience whilst getting to know a student, their capacities, their enthusiasms and their weaknesses is more problematic when a tutor and a student never meet.

Taught postgraduate students are often not only academically and culturally diverse but are also have very varied experiential backgrounds. A student may be offered a place on a course based on their prior work experience, particularly mature and international students who may bring less traditional academic qualifications but are experienced practitioners of their discipline. Many of these students are returning to education after a period of work in order to re-skill, or formalise their experience with an academic qualification, to improve their future employment prospects.

Literature focussing on the educational transition to postgraduate level study is limited [13]. The need to support incoming students to HE has been explored in a number of studies in recent years [14], [15], but these generally focus on the undergraduate and on-campus experience. Where students have unconventional academic backgrounds, or have been out of formal education for many years, induction and early formative feedback have been found to be vital [2]. For those choosing to study online, and at a distance, the potential for the transition to be a rocky step is more likely. Ensuring that these students are prepared and suitably supported as they step onto an MSc course need to be given due consideration by the course team.

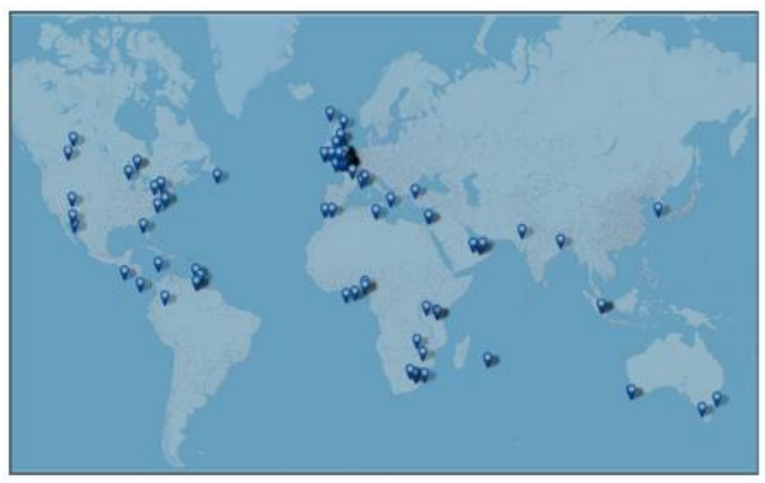

Figure 1. The spatial distribution of students enrolled on the MSc in GIS by distance learning (C) OpenStreetMap contributors)

For the distance learning community, diversity of location is also a factor for consideration and Figure 1 shows the current spatial distribution of students enrolled on the MSc in Geographical Information Systems (GIS), an ODL course offered by the School of Geography, University of Leeds, UK, for the last 15 years. This introduces time zone issues such as affecting the ability for synchronous group activities or increasing the response time to email queries.

Given the diversity of taught postgraduate students it is entirely conceivable that there are some gaps in the discipline, or subject-specific skills of incoming students.

The foundational modules of a study course may assume students have no prior knowledge of the principles and concepts being taught but there may well be an expectation that students have the required competencies in skills to engage with the module content from the outset. Where discipline-specific competencies need to be strengthened then methods to support incoming students may need to be put in place [16] but reaching the baseline skills can be a steep learning curve for some students making the transitional experience overwhelming. If this is the case then it is important that the educators identify gaps and provide support early in the students' learning journey which, in turn, can improve student satisfaction and retention and ultimately contribute to academic success.

\section{Overview of the teaching enhancement project}

As part of a funded teaching enhancement project, an exploration into whether pre-sessional resources, that were course-specific, may better support students in their transition to taught postgraduate studies was carried out. Prior to designing and developing these additional resources existing students were consulted to gain a better understanding of their experience of 'stepping-up' to a postgraduate degree and to provide an insight into what would have prepared them, or set clearer expectations, for their future studies. This evaluation was undertaken via a questionnaire to students taking modules or courses with Geographical Information Systems (GIS) components in the School of Geography at the University of Leeds, UK and included students enrolled on full-time campus-based and part-time ODL courses.

Objectives of the survey were to gain an understanding of why these students decided to study online versus enrolling on a campus-based course, and to evaluate whether there was a difference in the technical and quantitative data handling skillsets of students embarking on a degree depending on the mode of study. Assessing whether the students recognised that extra support was needed in order for them to successfully 'step-up' to taught postgraduate studies, or whether they felt disadvantaged if certain skills were 
missing at the start of their studies, provided further insight.

\subsection{GIS and the study cohort}

An understanding of why quantitative methods and technical skills are important to a degree in GIS underlies this study. A popular definition of GIS is that it is "a powerful set of tools for collecting, storing, retrieving at will, transforming, and displaying spatial data from the real world" [17] but, for many, GIS (or GI Science) focuses on its scientific and applied basis, by finding solutions to problems arising from the handling of spatial information in GI Systems [18].

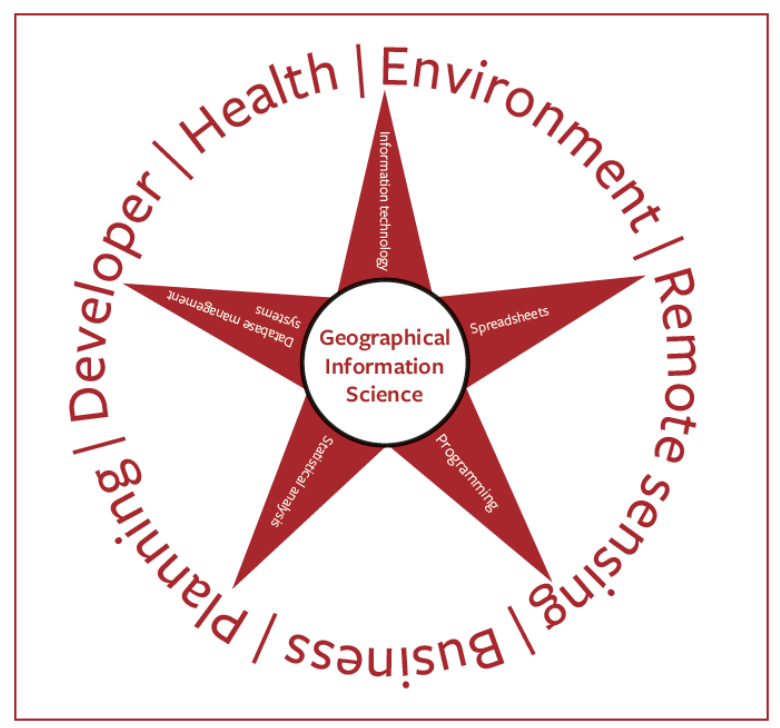

Figure 2. Example applications of Geographical Information Science

A taught postgraduate degree in GIS will typically have a scientific core requiring skills in the use of information technology and good quantitative data analysis competencies. Figure 2 depicts a selection of application areas (Environment, Remote Sensing, Business, Planning, Developer and Health) reflecting broad pathways that might be chosen by students on GIS courses, but the application of GIS can be found in most walks of life where a spatial context to decisionmaking or problem solving is required. The skills and competencies of a GIS expert working in these application areas are diverse but this project has focused on data handling skills such as the familiarity with statistical software, spreadsheets and databases and technical skills such as programming.

Due to the applied and varied nature of a GIS course, the students often enrol with a mixture of geographical, science, computing and mathematical backgrounds but not necessarily experience or competency in all. The foundational modules of the course may assume students have no prior knowledge of the principles and concepts being taught but there is an expectation that students have the skills and aptitude to engage with the module content from the outset.

The University of Leeds has an ongoing commitment to distance learning, as exemplified by the School of Geography which has been offering an online MSc in GIS, in collaboration with the University of Southampton, for almost 15 years [1]. The School also offers a full and part time campus-based MSc in GIS, with students on other courses, both within the School and in the wider University community, attending some of these modules. There are synergies between modules taught online and on-campus including, where possible, content and tutor. Due to the different dynamics of the two programmes, comparable campus-based and ODL modules are not normally run concurrently, nor are the cohorts combined to be taught as a single cohort, although there are occasions when a campus-based student may replace a module with the ODL version under certain circumstances.

Given this backdrop of two cohorts of students (campus-based and ODL) taking similar modules, these students were chosen as the study cohort to explore the ability and confidence levels in certain technical and quantitative data handling skills at the point of enrolment.

\subsection{Initial student survey}

Initial findings were obtained via an online questionnaire, seeking students' perceptions of their confidence in a selection of academic skills at the start of their studies and undertaking an audit of students' technical and data handling skills. The study invited 178 students, comprising 95 campus-based students (across 4 courses, but all with a GIS component) and 83 students enrolled on the GIS distance learning course to complete the survey.

The majority of campus-based students were studying full-time over a one year period; the timing of the survey was such that most students had just completed the taught element of their course and were about to embark on their dissertation so were approximately two-thirds of the way through their study. The stage of study was less clear-cut for distance students as there are four intakes a year (January, April, July and October); it is a part-time course with exit points after one year (the Postgraduate Certificate award), after two years (Postgraduate Diploma award) or after three years (Master of Science award) with the addition that some students are taking one or more credit-bearing modules for continuing professional development. Regardless of the stage of study, or anticipated award, it was not felt necessary in this early 
investigation to categorise these distance learning students further as they had all undergone a similar admissions process and it was the skills at point of entry that were of relevance to the study.

When comparable courses exist as both campusbased and distance learning, an analysis of the motivation behind a student's choice of one mode of study over another could be extremely useful to course leaders. In the questionnaire students were asked which factors had been important to them when selecting their course. Distance learning students were also asked whether they had studied online previously. The possible responses included pre-selected options for reasons for choosing a particular course and method of study but also included an open text box.

Recognition by students of their readiness for taught postgraduate studies and the extra support that they might need was explored via a series of questions asking students to rate their confidence level at the point of starting their first taught module and similarly rating their confidence at the current point in their studies. These questions focused on the academic literacy skills (for example, critical thinking and referencing) and institutional systems interfaces (such as the virtual learning environment and the library services). Some institution-wide resources already exist to enhance course-specific induction and orientation processes but feedback may be useful to inform on future developments.

Identifying the technical and quantitative data handling skills of students at point of entry could indicate where additional resources could be prioritised to support the students in their transition to taught postgraduate studies. All students were required to select their course of study before an audit of their skills was carried out to allow comparison between those enrolled on a campus-based course and those on the ODL course. Students were asked to indicate their previous experience and competency in GIS, spreadsheets, databases, statistical software and programming and were asked to suggest other resources that might support their skills baseline.

\subsection{Results of survey}

Of the 178 students targeted by the survey, 50 responded (response rate $=28 \%$ ). The respondents were close to an even split across campus-based and distance learning students (48\% campus-based; $52 \%$ distance learning). Of those 50 respondents, $56 \%$ stated they were UK students, 4\% European Union students and $38 \%$ international students. $70 \%$ reported that English was their first language.

The most popular reason stated for choosing ODL study was the flexibility of online study with the good reputation of the University being the outstanding reason given for enrolling in the campus-based courses. Further analysis of this question may enlighten course leaders on the thinking processes of students in their choice of degree, location, method of delivery and provide insight into recruitment trends and inform curriculum reviews.

Respondents were asked a range of questions to ascertain their confidence in a variety of academic skills, such as critical thinking, referencing, and independent study, both at the start of their ongoing studies and at their current stage of study. Whilst this gave a wider overview of the students' strengths and weaknesses (and could be evaluated in more depth in the future) the scope of this teaching enhancement project was limited and therefore the immediate followup actions were focused on the quantitative data handling and technical skills of the students.

Table 1. Percentage of students expressing expertise level (prior to commencement of current MSc studies) in a variety of software and skills

\begin{tabular}{|l|c|c|c|c|}
\hline $\begin{array}{l}\text { Expertise } \\
\text { Level: }\end{array}$ & $\begin{array}{c}\text { None } \\
\%\end{array}$ & $\begin{array}{c}\text { Basic } \\
\%\end{array}$ & $\begin{array}{c}\text { Inter- } \\
\text { Mediate } \\
\%\end{array}$ & $\begin{array}{c}\text { Adv- } \\
\text { anced } \\
\%\end{array}$ \\
\hline \multicolumn{5}{|c|}{ GIS } \\
\hline $\begin{array}{l}\text { Campus- } \\
\text { based }\end{array}$ & 37.6 & 29.1 & 25.0 & 8.3 \\
\hline ODL & 7.6 & 38.5 & 38.5 & 15.4 \\
\hline Combined & 22 & 34 & 32 & 12 \\
\hline \multicolumn{5}{|c|}{ Spreadsheet software } \\
\hline $\begin{array}{l}\text { Campus- } \\
\text { based }\end{array}$ & 8.3 & 37.5 & 37.5 & 16.7 \\
\hline ODL & 0 & 34.6 & 50.0 & 15.4 \\
\hline Combined & 4 & 36 & 44 & 16 \\
\hline \multicolumn{5}{|c|}{ Database software } \\
\hline $\begin{array}{l}\text { Campus- } \\
\text { based }\end{array}$ & 66.6 & 29.2 & 0 & 4.2 \\
\hline ODL & 34.6 & 42.3 & 23.1 & 0 \\
\hline Combined & 50 & 36 & 12 & 2 \\
\hline \multicolumn{7}{|c|}{ Statistical software } \\
\hline $\begin{array}{l}\text { Campus- } \\
\text { based }\end{array}$ & 33.3 & 45.8 & 16.7 & 4.2 \\
\hline ODL & 53.8 & 34.6 & 11.6 & 0 \\
\hline Combined & 44 & 40 & 14 & 2 \\
\hline $\begin{array}{l}\text { Campus- } \\
\text { based }\end{array}$ & 79.2 & 12.5 & 8.3 & 0 \\
\hline ODL & 76.9 & 19.3 & 3.8 & 0 \\
\hline Combined & 78 & 16 & 6 & 0 \\
\hline
\end{tabular}




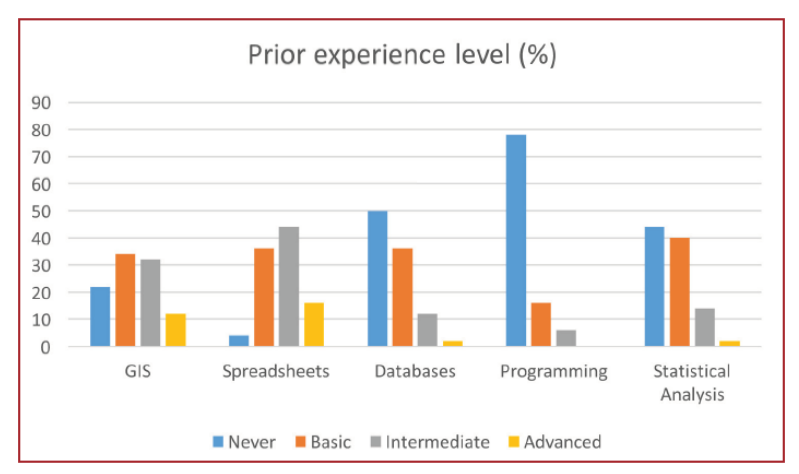

Figure 3. Skills audit of students at the start of their taught postgraduate studies

The survey asked respondents to state whether they had experience of a range of software, prior to the start of their current course. If the respondent had experience then they were asked to rate their level of expertise, as either 'Basic', 'Intermediate' or 'Advanced'. Table 1 shows the percentages of students expressing expertise levels in GIS, spreadsheet software, database software, statistical software and programming, based on their mode of study and combined. Comparing the responses between campus-based and ODL students the biggest difference was to be seen in the percentage who stated that they had not used GIS before; whilst 37.6\% of campus-based students were new to using GIS, only $7.6 \%$ of ODL had no prior experience. Similarly, a greater percentage of ODL students had some experience of database software but conversely, when it came to statistical software, the campus-based students were slightly more experienced. The expertise level for programming skills were similar across both groups and in both cases the majority of students had no prior experience.

The combined responses are further illustrated in Figure 3, demonstrating the range of skill levels; the most noteworthy result was that $78 \%$ of students had never done any programming prior to their current studies, and of those who had programmed before only $6 \%$ rated themselves as intermediate level with none describing themselves as advanced level programmers.

\subsection{Development of a pre-sessional resource}

The results determined that pre-sessional support for students who had no, or limited, programming experience prior to starting their GIS studies should be the priority of this teaching enhancement project. Given the limited time frame of the study it was decided that an existing resource would be the basis of a new resource; a resource used by academic colleagues with school children to introduce programming and agent based modelling in the context of modelling how disease spreads and how to slow or stop it altogether was adapted into a format consistent with other modules on the MSc GIS by distance learning course. The resource builds on the Susceptible-Infected-Recovered (SIR) model as illustrated in Figure 4. It is used in health-related GIS applications to calculate the number of susceptible, infected and recovered people within a population and can be used, for example, to estimate the number of people needing medical attention during an epidemic. The model was first proposed by Kermack and McKendrick in 1927 [19].

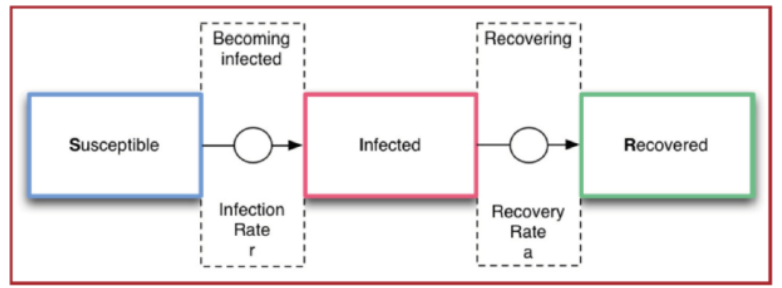

Figure 4. The Susceptible-Infected-Recovered model [19]

The resource was made available, upon request, to 30 ODL students and was distributed in Portable Document Format (PDF). It consisted of notes and a practical exercise and was aimed at students with no experience of coding (but equally suitable as a refresher course for students with some programming or modelling skills but where the application to topics that have a geographical component is new).

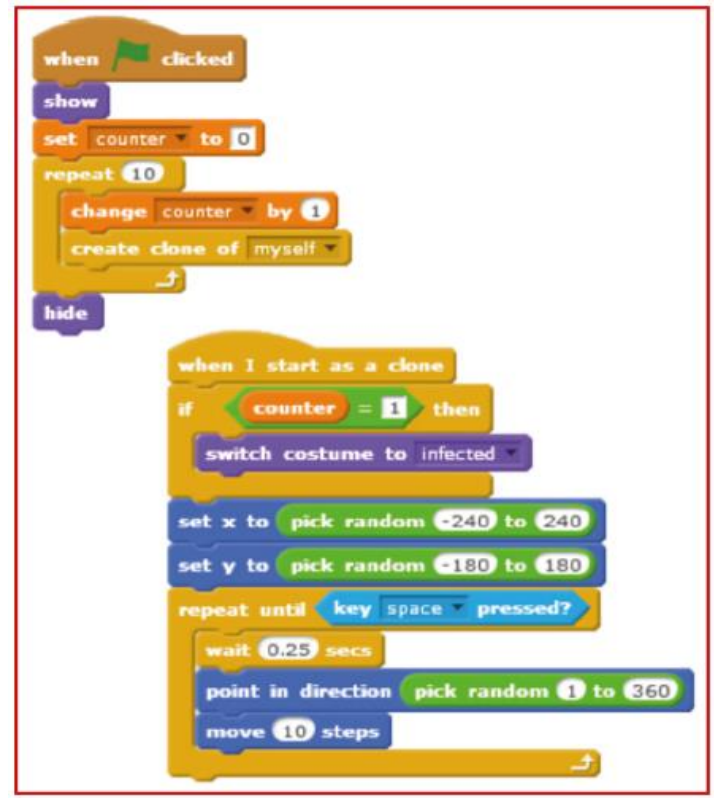

Figure 5. Using 'Scratch' to build a model of disease spread; an extract of the code 
The resource provided a flavour of the type of learning activities that students might encounter throughout their current studies and was designed as a short, non-assessed activity that could help build confidence and broaden experience but required little or no input from academic staff and could be completed independently. The practical allowed students to experiment with, and build their own, computer simulation of disease outbreak and explore how to slow or stop the spread of disease and reflect on the importance of geography in such situations. No specialist software was required but access to an internet browser, and registration to use the free programming language 'Scratch' (developed by MIT) was needed to undertake the practical. Scratch uses drag-and-drop coding blocks to build up code in an interactive interface as exemplified in Figure 5. A model answer was made available to students upon completion of the practical to compare against their results.

\subsection{Pedagogical basis of the study}

Students were instructed to work through the stepby-step Scratch tutorial and then think about how they could develop a more realistic model. For those students with a programming experience there was the opportunity to develop the model in a different programming language. Questions were posed in the resource notes that encouraged reflection on ideas and suggestions for changes to the model.

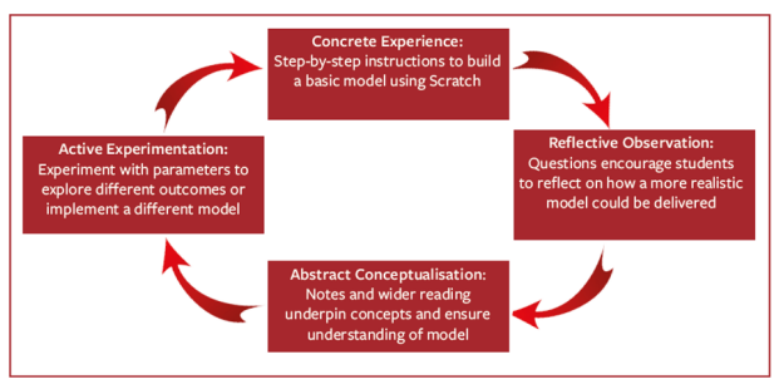

Figure 6. Adaptation of the Kolb Learning Cycle [20]

The approach of encouraging discovery and experimentation in this pre-sessional resource can be viewed as an adaptation of Kolb's Experiential Learning Cycle [20] as shown in Figure 6 whereby the 'Concrete Experience' is the step-by-step instructions to build the basic model using Scratch, the 'Reflective Observation' is the set of questions posed to students encouraging them to reflect on how a more realistic model could be delivered, the 'Abstract Conceptualisation' is ensuring students have full understanding of the model and its approach, underpinned by the notes and directed wider reading, and the 'Active Experimentation' is realized by exploring different outcomes by changing parameters or, for the more advanced programmers, implementing a different model using a different programming language.

\section{Evaluation and reflection on the student experience}

The study materials released to students related to programming (coding) and modelling (with a spatial/geographical context) and were intended as selfdirected, non-supported resources to introduce some foundational concepts and skills that may help students in their ongoing studies and future career. The learning resource carried no credit and contained no assessment.

Students were given several weeks to complete the resources, falling at a time when most students were either new to the course and had not started their studies or were in the 2 week rest period between modules. Students who accessed the resource were asked to provide feedback on the resource as would be usual procedure in any assessed module. Standard Likert scales were used to assess students' satisfaction with the resource, its content quality and personal and professional development opportunities. In addition, student were asked to give an indication of their previous programming experience, study plans regarding the two 'Developer' modules available within the GIS course, whether they had completed the resource and, if not, why not and how long was spent working through the notes and practical.

There was a $53 \%$ response rate to the resource evaluation $(\mathrm{N}=16)$. The response to the completion status of the resource indicated that $94 \%$ of respondents completed, or partially completed, the practical exercise. Reasons cited for not completing were mainly lack of time, though some cited that they had not completed because it was too difficult, whilst others did not complete because the programming element was considered too childish or simple. Most students spent between 2 and 5 hours working through the resource. Whilst $50 \%$ of respondents had done no programming in their previous studies, and $19 \%$ of respondents had no prior programming experience, it was noted that $43 \%$ of respondents planned to take a programming module as part of their current studies. Only $6.3 \%$ of students who had previously intended to take a programming module as part of their current studies stated that they no longer wished to having completed this resource.

The quantitative feedback, as shown in Table 2, demonstrated that the resource was positively received by most students. 
Table 2. Student evaluation of resource

\begin{tabular}{|l|c|c|c|}
\hline & $\begin{array}{c}\text { Agree } \\
\%\end{array}$ & $\begin{array}{c}\text { Neither } \\
\text { Agree } \\
\text { or } \\
\text { Disagree } \\
\%\end{array}$ & $\begin{array}{c}\text { Disagree } \\
\%\end{array}$ \\
\hline $\begin{array}{l}\text { Satisfied with } \\
\text { the quality of } \\
\text { resource }\end{array}$ & 87.5 & 12.5 & 0 \\
\hline $\begin{array}{l}\text { Fully engaged } \\
\text { with resource }\end{array}$ & 87.5 & 12.5 & 0 \\
\hline $\begin{array}{l}\text { Study materials } \\
\text { were of a high } \\
\text { standard }\end{array}$ & 87.5 & 12.5 & 0 \\
\hline $\begin{array}{l}\text { Intellectually } \\
\text { stimulating }\end{array}$ & 87.5 & 12.5 & 0 \\
\hline $\begin{array}{l}\text { Developed } \\
\text { skills useful in } \\
\text { my career }\end{array}$ & 75 & 12.5 & 12.5 \\
\hline $\begin{array}{l}\text { Developed } \\
\text { skills useful for } \\
\text { my GIS studies }\end{array}$ & 75 & 18.8 & 6.3 \\
\hline
\end{tabular}

Qualitative feedback to the resources suggest that the resource was extremely well-received with reactions ranging from passing enjoyment and/or interest, to recognition of giving an insight into choice of streams and/or optional modules, through to acknowledgement of experimentation and development of existing programming skills, as demonstrated in the following comments:

"I really liked the background notes to the practical. I found it very interesting and felt keen to do the practical as I was reading."

"The whole "game" concept to produce a geographic/scientific results is a great ideas, very stimulating, surprising."

"Easy to follow the guide. I didn't feel hopelessly stuck at any point. It encouraged a bit of thought about what you were doing and how it relates to the real world. I do like that the code is very interactive and broken down into blocks of different colours which makes the code easy to review and build once you know what blocks are available and where to find them."

"It will definitely help someone new to programming to understand programming concepts. The exercise is also a very good introduction to programming for GIS students who are interested in the programming modules."
"Ijust wanted to say thank you. This type of exercise really helps in getting a glimpse of what a specific module or stream might entail, thus allowing one to have more of an informed perspective when deciding which modules to pursue."

"It let me generate my own program without the need to actually know the language, which is the intricate part that normally comes along with coding. It also let me to test out different scenario in order to see now the 'infections' are spreading. This might come handy should one day I need to quickly model certain simple scenarios in my career path"

Aspects that students felt could be improved related more to practical outputs that did not work out as they expected, due to difficulty of the tasks or apparent lack of clarity in the instructions. Conversely, other views were that the programming exercise could be more challenging, as demonstrated in the following comment:

"Using a more advance coding program - Scratch felt a bit too childish and didn't seem to transferable to future study/careers"

The decision to use Scratch was due to its ease of application so that students could build a model effortlessly and independently. For students that had previous programming experience this response that Scratch felt too 'childish' is not unexpected. Whilst the technical aspects may be too easy for this particular student, working through the resource may have extended their knowledge in a previously non-familiar application area, i.e. modelling the spread of disease which could, in turn, benefit their future career and study opportunities in GIS.

The final question of the survey asked students whether they would like to have access to more topicbased resources to support their studies. $87.5 \%$ of students said that they would and listed topics such as revision resources on analytical and mathematical concepts, an introduction to specific GIS terminology, resources introducing basic data sources, examples of cases studies, remote sensing refresher materials and more coding exercises.

Whilst this project has come to the end of its funded phase, the research and evaluation undertaken during the project may provide the foundations for a framework of future developments, with a remit for the wider dissemination of the benefits of course-specific, pre-sessional (or transitional) resources. Opportunities can be explored to share future resources with the wider academic community, starting with future intakes of campus-based students taking a degree in GIS at the University of Leeds and then rolling out similar 
resources to other courses requiring strong quantitative methods or technical skills. This might include collaboration with colleagues who offer campus-based, pre-sessional English courses to new students; there is a growing demand for language courses to deliver content-driven activities as a way of introducing students to discipline-specific terminology. Another interesting follow-on study could be to explore whether the introduction of these pre-sessional resources results in an improvement in overall academic attainment.

\section{Conclusion}

This paper has evaluated the perceived readiness of students embarking on a postgraduate degree containing a GIS component and has explored the potential for better supporting the course-specific skills of ODL students. The results of this study would suggest that students would value the development of a suite of pre-sessional resources in a variety of quantitative methods and technical skills areas to better prepare them for their studies.

The resource developed for this study has allowed students to self-evaluate their aptitude for programming before they selected a module with a coding emphasis; feedback from students suggested that being given the opportunity to develop simple programming skills and reflect upon and experiment with those skills, prior to committing to a programming-based module, was wellreceived and beneficial to their study plans. For those students who found the resource too difficult or not relevant to their study or career paths then this insight into a programming module may have saved later dissatisfaction or distress.

Given the completion rate and positive response from the students given access to the resource, the perception that students would value more support has been proven and the incentive for the development of more self-directed, stand-alone resources to introduce course-relevant skills and techniques has been generated.

The scope of this teaching enhancement project was limited but the initial survey across campus-based and ODL students, and the subsequent evaluation of a presessional resource introducing programming, have captured valuable information that have the potential to be useful in a series of follow-on studies.

\section{References}

[1] Durham, H., (2017) 'Enhancing the Transitional Experience of Taught Postgraduate Students:A Case Study from an Online Distance Learning Programme in Geographical Information' in Proceedings of the 9th International Conference on Education and New Learning
Technologies, EDULEARN17: Barcelona, Spain. pp. 55035509.

[2] Durham, H. and See, L., (2015) 'Lessons Learned from Distance Learning' in Masters Level Teaching, Learning and Assessment: Issues in Design and Delivery (P. Kneale, ed.), Palgrave: London, pp.209-217.

[3] Durham, H., (2017) 'Opinion: Will Online Distance Learning Mean the End of Campus-Based Programmes?' Leeds Institute for Teaching Excellence: Blog; http://teachingexcellence.leeds.ac.uk/ (27 February 2018).

[4] University of London, (2018) 'The Birthplace of Long Distance Learning', History of University of London; https://london.ac.uk/_(27 February 2018).

[5] Open University, (2017) 'Learning, Teaching and Research', History of the OU, OU; http://www.open.ac.uk/ (27 February 2018).

[6] Kaplan, A.M. and Haenlein, M., (2016) 'Higher Education and the Digital Revolution: About MOOCs, SPOCS, Social Media, and the Cooke Monster', Business Horizons, vol. 59, pp. 441-450.

[7] Open University, (2017) 'Small Screen Heroes: The OU and the BBC', History of the OU; OU; http://www.open.ac.uk/ (27 February 2018).

[8] Statista, (2017) 'Number of Internet Users Worldwide from 2005 to 2017 (in millions)', Internet, Demographics \& Use; https://www.statista.com/statistics/273018/number-ofinternet-users-worldwide/ (27 February 2018).

[9] Office for National Statistics, (2017) 'Statistical Bulletin: Internet Users in the UK: 2017', IT and Internet Industry, ONS; https://www.ons.gov.uk/ (1 March, 2018).

[10] Allen, I.E and Seaman, J., (2017) 'Distance Education Enrollment Report 2017', Digital Learning Compass; https://onlinelearningsurvey.com/reports/digtiallearningcom passenrollment2017.pdf_(27 February 2018).

[11] Talbot, C., (2016). Studying at a Distance: A Guide for Students. $4^{\text {th }}$ ed. Open University Press

[12] Wozniak, H., (2016) 'Get Ready, Get Learning: Investigating university students' transition to online distance learning in the health sciences', PhD thesis. Charles Darwin University, 346p.

[13] Tobbell, J. and O'Donnell, V.L., (2015) 'Transition Issues for Course Designers: 4.1. Transition to Postgraduate Study: Overlooked and Underestimated' in Masters Level Teaching, Learning and Assessment: Issues in Design and Delivery ( $P$. Kneale, ed.), Palgrave, London, pp. 57-61.

[14] Knight, J. and Rochon, R., (2012) 'Starting Online: Exploring the Use of a Social Networking Site to Facilitate Transition into Higher Education', The Electronic Journal of e-Learning, vol. 10, no.3, pp. 257-261.

[15] Edwards, J.A., (2012) 'Creating an Integrated Online Learning Module for Information Literacy, Academic Writing and Communication Skills: a Case Study', Middlesex Journal of Educational Technology, vol. 2, no. 1, pp. 51-59. 
[16] Perkin G. and Bamforth, S., (2011) "A variety of approaches to the provision of mathematics help for first-year engineering undergraduates", International Journal of Electrical Engineering Education vol. 48, no. 1, pp. 79-91.

[17] Burrough, P.A., (1986) Principles of Geographical Information Systems for Land Resources Assessment, Oxford University Press, Oxford

[18] Goodchild, M.F., (1992) "Geographical Information Science", International Journal of Geographical Information Systems, vol. 6, pp. 31-45.

[19] Kermack, W.O. and McKendrick, A.G., (1927) A Contribution to the Mathematical Theory of Epidemics. Proceedings of the Royal Society of London. 115, pp700-721.

[20] Kolb, D. A., (1984) Experiential learning: Experience as the source of learning and development (Vol. 1), PrenticeHall., Englewood Cliffs, NJ.

\section{Acknowledgements}

The author is grateful to the Leeds Institute for Teaching Excellence (LITE) for supporting and funding this teaching enhancement project which ran from 1 January-31 December 2017 The modelling disease resource was adapted with kind permission from content developed by Dr Andy Evans and Professor Alison Heppenstall, University of Leeds. 